\title{
AXIAL CRACK PROPAGATION AND ARREST IN PRESSURIZED FUSELAGE1
}

\author{
M. Kosai, A. Shimamoto ${ }^{2}$, C.-T. Yu, S.I. Walker, A.S. Kobayashi and P. Tan ${ }^{3}$ \\ University of Washington \\ Department of Mechanical Engineering \\ Seattle, WA \\ SUMMARY

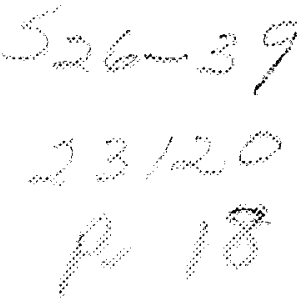

The crack arrest capability of a tear strap in a pressurized precracked fuselage was studied through instrumented axial rupture tests of small scale models of an idealized fuselage. Upon pressurization, rapid crack propagation initiated at an axial through crack along the stringer and immediately kinked due to the mixed modes I and II state caused by the onesided opening of the crack flap. The diagonally running crack further turned at the tear straps. Dynamic finite element analysis of the rupturing cylinder showed that the crack kinked and also ran straight in the presence of a mixed mode state according to a modified two-parameter crack kinking criterion .

\section{INTRODUCTION}

The role of a tear strap in an airplane fuselage is to arrest an axial crack which is propagating either subcritically under fatigue loading or dynamically after reaching criticality. Such crack arrest can occur at lower stress due to the reinforcing effect of the tear strap or by crack kinking due to the complex crack tip stress field generated by the crack flap and the tear strap. The latter provides controlled damage and depressurization of the fuselage. Although the tear strap is the last defense of an axially rupturing fuselage, little is known about its effectiveness in arresting the crack. Thus, much of the tear strap design is based on empirical rules derived from sub- and full-scale testing of pressurized fuselages. Literature is abundant with analytical and experimental papers dealing with axial fatigue crack extension and possible arrest in idealized and actual fuselages but few consider crack kinking and flapping as an arrest criterion. The first theoretical paper dealing crack kinking and flapping as an arrest criterion appears to be that of Kosai and Kobayashi (1991).

\footnotetext{
This research was supported by the Federal Aviation Administration Grant No. 92-G-0005.

On leave from Saitama Institute of Technology, Okabe, Saitama, Japan at the time of this investigation.

Federal Aviation Administration, Technical Center, Atlantic City International Airport, NJ.
} 
In the above mentioned paper, the axial crack was assumed to open symmetrically, i.e. mode I crack tip deformation, in a fuselage reinforced by longitudinal stringers, frames and tear straps. The crack-tip plastic zone associated with this symmetric axial crack exceeded 102 $\mathrm{mm}$ (4 in.) with the axial stress ahead of the crack tip exceeding $345 \mathrm{MPa}(50 \mathrm{ksi})$. This large axial stress was generated through axial stretching of two crack flaps and was the cause of crack kinking as described by Kobayashi et. al. (1988). If, however, failure were to occur along the multiple site damages (MSD's) in a lap joint, evidences [Sampath and Broek (1991); NTSB (1989)] show that fracture occurs in the upper skin with the lower skin still attached to the stringer. The axial stretching due to the resultant one-sided crack flap would then generate axial tensile stresses along the cracked upper skin and imposed a mode II state at the crack tip. The importance of mode II deformation and the attendant mode II stress intensity factor, $\mathrm{K}_{\mathrm{II}}$, were also observed in a recent fatigue crack growth study of an idealized model of a stringer reinforced fuselage by Fyfe and Sethi (1991). Kosai and Kobayashi (1993) then postulated a crack propagation and kinking criteria in the presence of $\mathrm{K}_{I I}$ and reanalyzed the crack arrest capability of a tear strap in a pressurized fuselage.

\section{THEORETICAL BACKGROUND}

As mentioned previously, the function of a tear strap is not so much as to arrest a propagating axial crack by reducing the circumferential stress in the crack path, but to deflect the crack in the circumferential direction. The large opening due to crack flapping would then reduce the crack driving force through controlled depressurization of the cabin and thus arrest the crack. Such crack deflection is accomplished by the presence of mode II stress intensity factor, $\mathrm{K}_{\mathrm{II}}$, which is generated by the flap of the upper skin. The large crack flap also generates a large axial stress ahead of the propagating crack tip [Kobayashi, et. al. (1988); Kobayashi, et. al. (1988a)], and together with the reduced circumferential stress due to the presence of the tear strap, augments the propensity for crack kinking under a mixed mode crack tip deformation.

In a previous analysis [Kosai and Kobayashi (1991)], an elastic crack kinking criterion for a stationary mode I crack [Streit and Finnie (1980)] with plasticity correction was used to assess the effectiveness of the tear strap for a symmetric crack flap. The unsymmetric crack flap considered in this study, however, will generate a combined mode I and II crack tip deformation field [Fyfe and Sethi (1991)] and thus crack kinking is inherent in such crack tip deformation.

On the other hand, if the apparent mode I stress intensity factor, $\mathrm{K}_{\mathrm{I}}$, is elevated by the presence of a row of MSD's along the axis of the crack, then the crack will continue to propagate in the axial direction despite the presence of an inevitable crack tip bulging and the resultant $\mathrm{K}_{\mathrm{II}}$ in a pressurized fuselage [NTSB (1989)]. The physical evidence of such self similar crack extension along a row of MSD's in the presence of $K_{I I}$ thus requires a new crack propagation and kinking criteria. 
Previous experimental results [Arakawa (1991)] involving crack propagation in thin aluminum fracture specimens recorded maximum crack velocities of the order of 40 meters per second for the brittle 7075-T6 aluminum alloys. For the more ductile 2024-T3, the corresponding maximum crack velocity is estimated to be lower than 20 meters per second. At this low crack velocity, the crack tip state of stress can be approximated by its siatic counterpart despite the fact that the entire structural deformation must be treated dynamically. This greatly simplifies the theoretical analysis in this investigation.

Using the maximum stress criterion which is also identical with the maximum circumferential stress criterion in this case, and the crack tip stress field, the angle of crack kinking, $\theta_{\mathrm{C}}$ in the presence of $\mathrm{K}_{\mathrm{II}}$ was derived by Erdogan and Sih (1963). This maximizing condition yields a crack kinking criterion which predicts a positive $\theta_{\mathrm{C}}$ for a negative $\mathrm{K}_{\mathrm{II}}$ and a negative $\theta_{\mathrm{C}}$ for a positive $\mathrm{K}_{\mathrm{II}}$. In the absence of $\mathrm{K}_{\mathrm{II}}$, however, the Erdogan-Sih criterion predicts a self-similar crack propagation or $\theta_{C}=0$ and fails to explain the physically observed crack instability where crack kinking takes place in a $\mathrm{K}_{\mathrm{I}}$ field. The static elastic crack kinking criterion, which incorporates the second order term in the crack tip stress field, of Streit and Finnie (1980) or the dynamic counterpart of Ramulu and Kobayashi (1983) predicts such crack kinking and was found to agree well with available experimental data. This mixed mode fracture criterion can be represented as

$$
K_{I C}=K_{I} \cos ^{3} \frac{\theta_{C}}{2}-3 K_{I I} \cos ^{2} \frac{\theta_{C}}{2} \sin \frac{\theta_{C}}{2}+\frac{\sqrt{2 \pi r_{C}}}{2} \sigma_{O X}\left(1-\cos 2 \theta_{C}\right)
$$

where $r_{C}$ is a material property.

Equation (1) incorporates the second order effect into the Erdogan-Sih criterion and follows a similar trend where a positive $\theta_{C}$ is predicted for a positive $K_{I}$ and a negative $K_{I I}$, The crack kinking angle, $\theta_{\mathcal{C}}$, increases with increasing $\sigma_{\mathrm{OX}}$ where negative $\sigma_{\mathrm{Ox}}$ tends to stabilize the crack path. Equation (1) shows that for the same $\mathrm{K}_{\mathrm{I}}$ and. $\mathrm{K}_{\mathrm{II}}$ and positive $\sigma_{\mathrm{OX}}, \theta_{\mathrm{C}}$ $=0$ and the crack will propagate straight ahead.

The crack kinking angle can be obtained by maximizing the crack tip circumferential stress and results in the following transcendental equation:

$$
\begin{aligned}
& \frac{\mathrm{K}_{\mathrm{II}}}{\mathrm{K}_{\mathrm{I}}}=\frac{-\sin \frac{\theta_{\mathrm{C}}}{2}}{\left(3 \cos \theta_{\mathrm{C}}-1\right)}\left[2 \cos \frac{\theta_{\mathrm{C}}}{2}-\frac{16 \sqrt{2 \pi}}{3} * \mathrm{~A} * \cos \theta_{\mathrm{C}}\right] \\
& \mathrm{A}=\sqrt{\mathrm{r}_{\mathrm{C}}} \frac{\sigma_{\mathrm{OX}}}{\mathrm{K}_{\mathrm{I}}}
\end{aligned}
$$

The term, $A$, is related to the critical distance, $r_{C}$, from the crack tip and is proportional to the nonsingular stress, $\sigma_{\mathrm{ox}}$. For a pure mode I crack tip stress field, Ramulu and Kobayashi 
(1983) have shown that $r_{C}$ is a material dependent parameter which must be determined experimentally. Thus, Equation (1) incorporates the second order term and represents a mixed-mode extension of the crack kinking criterion by Streit and Finnie (1980) and Ramulu and Kobayashi (1983).

The crack extension criterion represented by Equation (1) and the crack kinking criterion represented by Equation (2) do not account for the elevation in stress intensity factors, $\mathrm{K}_{\mathrm{I}}$ and possible $\mathrm{K}_{\mathrm{II}}$, due to the presence of MSD. The effect of MSD obviously is to promote self-similar crack extension, as seen in the NTSB report (1989), and can be incorporated into this analysis by artificially increasing $\mathrm{K}_{\mathrm{I}}$ by a magnification factor which represents the interaction effect between the axial crack and the small crack emanating from adjacent
fastener holes.

After kinking under the presence of mixed mode, i.e. $\mathrm{K}_{\mathrm{I}}$ and $\mathrm{K}_{\mathrm{II}}$ crack tip loading, the crack could propagate under a pure mode I crack tip loading due to the lack of a constraining stringer. Continuous crack curving under such condition will require that

$$
\mathrm{r}_{\mathrm{O}}=\frac{9}{128 \pi}\left(\frac{\mathrm{K}_{\mathrm{I}}}{\sigma_{\mathrm{ox}}}\right)^{2}<\mathrm{r}_{\mathrm{c}}
$$

and the crack curving angle, $\theta_{\mathrm{C}}$ is

$$
\theta_{\mathrm{C}}=\cos ^{-1}\left[\frac{1 \pm \sqrt{1+\frac{1024 \pi}{9} \mathrm{r}_{\mathrm{C}}\left(\frac{\sigma_{\mathrm{OX}}}{\mathrm{K}_{\mathrm{I}}}\right)^{2}}}{\frac{512 \pi}{9} \mathrm{r}_{\mathrm{C}}\left(\frac{\sigma_{\mathrm{OX}}}{\mathrm{K}_{\mathrm{I}}}\right)^{2}}\right]
$$

The development of a flap and the constraints due to the tear strap and the frame most likely will reduce the dominant $\mathrm{K}_{\mathrm{I}}$ during the crack curving process and will result in crack arrest.

To reiterate, the proposed crack propagation and kinking criteria in the presence of mixed mode, $\mathrm{K}_{\mathrm{I}}$ and $\mathrm{K}_{\mathrm{II}}$, crack tip deformation provide the necessary analytical tools for assessing the possibility of crack flapping in the event of rapid axial propagation in a pressurized fuselage. 


\section{EXPERIMENTAL PROCEDURE}

The crack arrest capability of a tear strap in a pressurized fuselage was studied through instrumented, axial rupture tests of a small scale model of an idealized fuselage. Some of the details of the experimental procedure are described in the following.

\section{Specimen}

The test specimen consisted of a pressurized thin 2024-T3 aluminum cylinder of $360 \mathrm{~mm}$ diameter $\times 914 \mathrm{~mm}$ length $\times 0.3 \mathrm{~mm}$ thickness with one or two riveted and bonded lap or butt joint(s). Simulated tear straps were riveted and bonded to this scale model fuselage which was clamped between two steel cylinders of $406 \mathrm{~mm}$ diameter $\times 1219 \mathrm{~mm}$ length. This assembly represents the diameter-to-length ratio of a typical passenger plane. An axial through crack, $100 \mathrm{~mm}$ in length, was machined as a starter crack adjacent to a stringer and sealed with a cork gasket and silicon rubber sealant. The fuselage segment was instrumented with three to five strain gages along the anticipated crack path and a pressure transducer under the starter crack. A schematic layout of the fuselage model and the test fixture are shown in Figures 1 and 2, respectively.

\section{Test Procedure}

The test fixture was shielded to contain the flying debris which was generated by the explosive nature of the test. The strain gage and pressure transducer data was recorded on a magnetic tape recorder. To insure air tightness, the model was pre-pressurized at low pressure and checked for leaks which were then sealed with silicon rubber. Increasing pressure was applied to the scale model fuselage until a rapidly propagating axial crack initiated from the precrack.

High speed photographs of the rupturing scale model of the fuselage were taken by an IMACON 790 camera which was triggered by a crack wire in the crack path. Since the minimum framing rate of 10,000 frames/sec of this camera was too fast to record the entire rupture event, high speed photographs of four identical specimens were recorded at different time delays The composite picture obtained by assembling these four series of photographs provided a visual display of the large deformation associated with the one sided flap opening. 


\section{NUMERICAL ANALYSIS}

The unsymmetric crack tip deformation along the stringer required that at least one quarter of the scale model fuselage be considered as shown in Figure 3. The longitudinal stringers and the tear straps were modelled by beam elements. Implicit in this one-quarter segment modeling is an assumption, which was made to reduce the computational time, that an identical axial crack was also propagating in the other symmetric quarters of the fuselage. Because of the inevitable coupling effect between the two symmetrically propagating cracks, this modeling will not model correctly a very large crack flap opening of the single crack in the scale model fuselage.

One of the unknown quantities is the actual pressure distribution on the flap as the crack continues to open up. Previous numerical study on a rupturing full scale fuselage (Kosai and Kobayashi, 1993) showed that minor variation in the prescribed flap pressure yielded less than two percent variation in the crack tip stress intensity factor and thus the measured full pressure was prescribed on the opening flap.

The fracture parameters, $\mathrm{K}_{\mathrm{I}}, \mathrm{K}_{\mathrm{II}}$ and $\sigma_{\mathrm{ox}}$ were determined through an elasto-dynamic finite element code (FEM), which was executed in its generation mode by prescribing the measured crack velocity together with the time-varying applied loads, using shell elements. The stress intensity factors were computed through a calibrated crack tip stress [Kosai and Kobayashi (1993)]. The remote stress component, $\sigma_{\mathrm{ox}}$, was computed by subtracting the singular stress component from the axial stress component ahead of the crack tip.

The numerically determined $\mathrm{K}_{\mathrm{I}}, \mathrm{K}_{\mathrm{II}}$ and $\sigma_{\mathrm{ox}}$ are then used to assess the potential of self similar crack propagation or crack kinking as described in the section of Theoretical Background.

\section{RESULTS}

Ten cylinders, without the simulated tear straps, and eleven cylinders, with the tear strap of various configurations, as shown in Table 1, or a total of twenty-one rupture tests were conducted. Specimens of Type a-1 (Table 1-1), without the lap joint or stringer along the precrack, were tested to check in the absence of $\mathrm{K}_{\mathrm{II}}$, for crack curving due to the axial tensile stress generated by large crack flaps after Kobayashi et al (1988). The rapidly propagating crack did not bifurcate but turned abruptly and ran circumferentially along the two steel end-cylinders. Likewise, the crack in Type e-1 specimen (Table 3) ran axially until it hit the tear straps and then ran circumferentially along the tear straps. These results indicate that the flap was not large enough to develop sufficiently large axial tension to kink the running crack prior to reaching the two steel end-cylinders. 
For Type a-2 (Table 1), b-1, b-2 (Table 2) and d-1 (Table 3) specimens, the crack kinked immediately upon propagation and ran diagonally until it hit the steel end-cylinder. In this case, the crack kinked due to the presence of $\mathrm{K}_{\mathrm{II}}$ which was generated by the one-sided flap away from the lap joint and/or stringer.

For Type c-1, c-2 (Table 2) and c-3 (Table 3) specimens, the crack kinked immediately upon extension but then propagated in an off-axis direction until it approached the tear straps where it turned circumferentially and propagated along the tear straps. Figure 4 shows photographs, which are a composite of two tests, of a rupturing Type c-3 specimen. This sequential photograph shows the development of the crack flap after it kinked immediately upon extension,

Figure 5 shows typical strain gage results obtained during a rupture test. The strain gage results were used to estimate the crack velocities which ranged from 30 to 120 meters per second in all of the tests. This low crack velocity justified the use of the static crack tip equations of Equations 1 through 4 to extract the variation in the mixed mode stress intensity factors, $\mathrm{K}_{\mathrm{I}}$ and $\mathrm{K}_{\mathrm{II}}$, and the remote stress components, $\sigma_{\mathrm{ox}}$, with crack extension.

Figures 6 and 7 show the variations in $\mathrm{K}_{\mathrm{I}}, \mathrm{K}_{\mathrm{II}}$ and $\sigma_{\mathrm{ox}}$ with crack extension for Specimen No. 11 (Type e c-3) and Specimen No. 13 (Type b-2). Since Figure 7 shows that $K^{d y n_{I}}>K_{I C}$ in Specimen No, 13, the crack will not kink despite the fact that the computed $r_{o}>r_{c}$ according to the crack kinking criterion set forth in the Theoretical Background. On the other hand, crack kinking will occur at the onset of rapid crack propagation in Specimen No. 11 due to the presence of $K_{I I}$ and $r_{0}>r_{c}$. The good agreement between the predicted and the measured crack kinking angles and the subsequent self similar crack extension demonstrated the effectiveness of the crack kinking criterion as applied to a rupturing fuselage. The legend in Figure 6 shows that the crack kinking angle estimated without the $\sigma_{\text {ox }}$ term is $1 / 2$ of that measured.

Five of the twnety-one small-scale fuselage test results were analyzed using the procedure describe above. In all cases, the modified crack kinking criterion of Kosai et al correctly predicted the experimentally crack kinking angles.

\section{CONCLUSIONS}

A hybrid analysis, which utilizes the test results of a rupturing small-scale fuselage model to drive a large deformation, elastodynamic finite element code, was effectively used to study the mechanics of the crack arrest at a tear strap in a pressurized fuselage.

The modified crack kinking criterion of Kosai et al (1993) will predict the crack kinking angle in the small-scale fuselage test specimens. 


\section{BIBLIOGRAPHY}

Arakawa, K., Drinnon, R.H., Jr., Kosai, M. and Kobayashi, A.S. (1991). "Dynamic Fracture Analysis by Moire Interferometry," Experimental Mechanics, 31 306-309.

Erdogan, F. and Sih, G.C. (1963). "On the Crack Extension in Plates Under Plane Loading and Transverse Shear," Journal of Basic Engineering, 85 519-527.

Fyfe, I.M. and Sethi, V. (1991). "The Role of Thin Cylinder Bulging on Crack Curvature," AIAA Paper 914086, 32nd Structures, Structural Dynamics and Materials Conference, Baltimore, MD.

Kobayashi, A.S., Emery, A.F., Love, W.J. and Chao, Y.H. (1988). "Subsize Experimental and Numerical Modeling of Axial Rupture of Gas Transmission Lines," ASME Journal of Pressure Vessel Technology, 110, 155-160.

Kobayashi, A.S., Emery, A.F., Love, W.J., Chao, Y.H. and Johannsen, O. (1988a). "Crack Bifurcation and Arrest in Pressurized Pipe," Fracture Mechanics: Nineteenth Symposium, ASTM STP 609, ed. T.A., Cruse, ASTM, 441-465.

Kosai, M. and Kobayashi, A.S. (1991). "Axial Crack Propagation and Arrest in Pressurized Fuselage," Structural Integrity of Aging Airplanes, eds. S.N. Atluri, S.G. Sampath and P. Tong, Springer-Verlag, 225-239.

Kosai, M., Kobayashi, A.S and Ramulu, M. (1993). "Tear Straps in Airplane Fuselage," to be published in Structural Integrity of Aging Airplanes, eds. S.N. Atluri, S.G. Sampath and P. Tong, Technological Publications, Atlanta, GA.

Maclin, J.R. (1991). A paper presented at the 1991 International Conference on Aging Aircraft and Structural Airworthiness, Washington, D.C.

National Transportation Safety Board Aircraft Accident Report. (1989). "Aloha Airlines Flight 243, Boeing 737-200, N73711, Near Maui, Hawaii, April 28, 1988," NTSB/AAR$89 / 03$.

Ramulu, M. and Kobayashi, A.S. (1983). "Dynamic Crack Curving - A Photoelastic Evaluation," Experimental Mechanics, 23, 1-9.

Sampath, S. and Broek, D. (1991) "Estimation of Requirements of Inspection Intervals for Panels Susceptible to Multiple Site Damage," Structural Integrity of Aging Airplanes, eds. S.N. Atluri, S.G. Sampath and P. Tong, Springer-Verlag, 339-389.

Streit, R. and Finnie, I. (1980). "An Experimental Investigation of Crack Path Directional Stability," Experimental Mechanics, 20, 17-23. 
Table 1. Small-Scale Fuselage Specimens

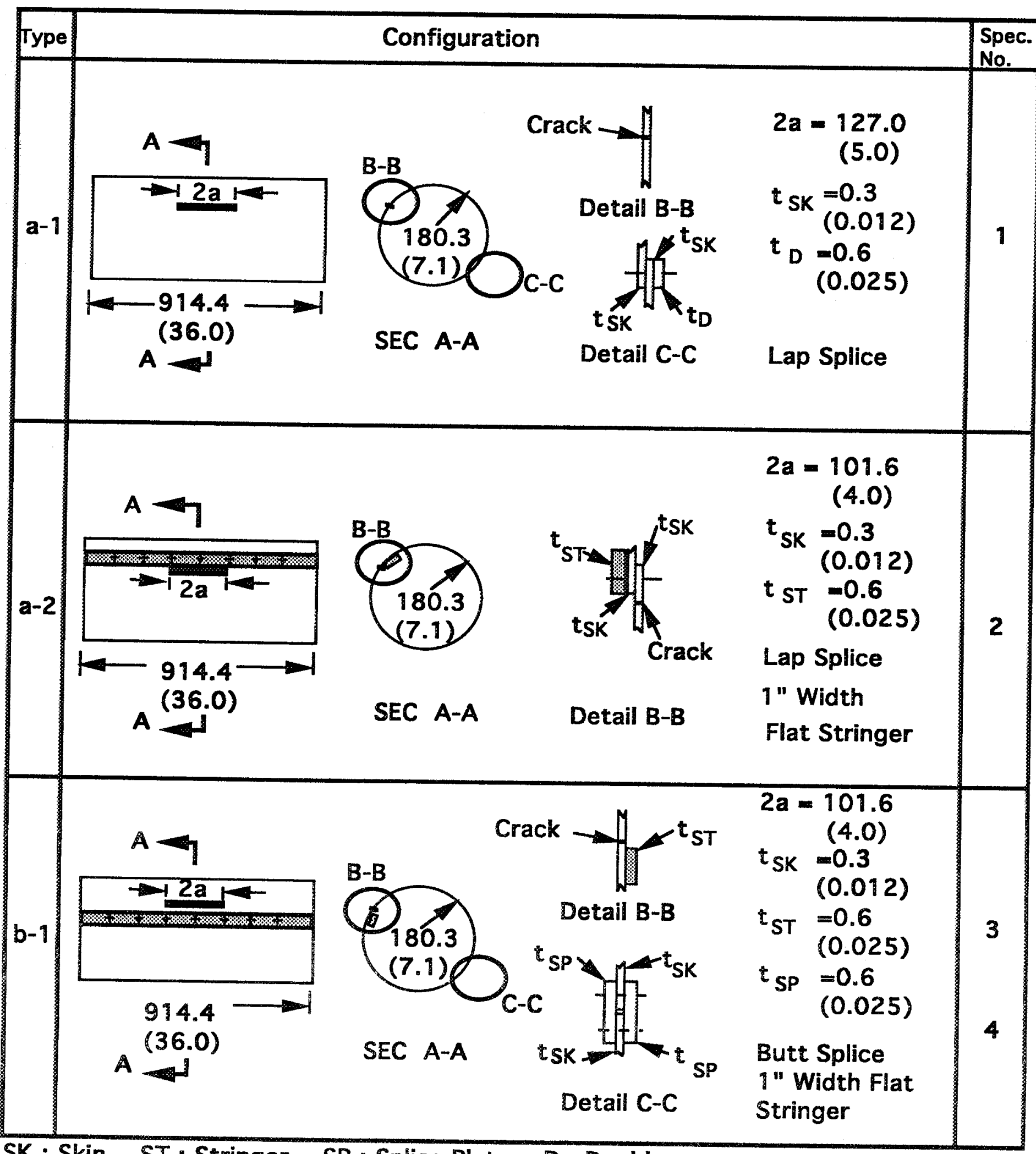

SK : Skin ST: Stringer SP : Splice Plate D : Doubler 
Table 2. Small-Scale Fuselage Specimens

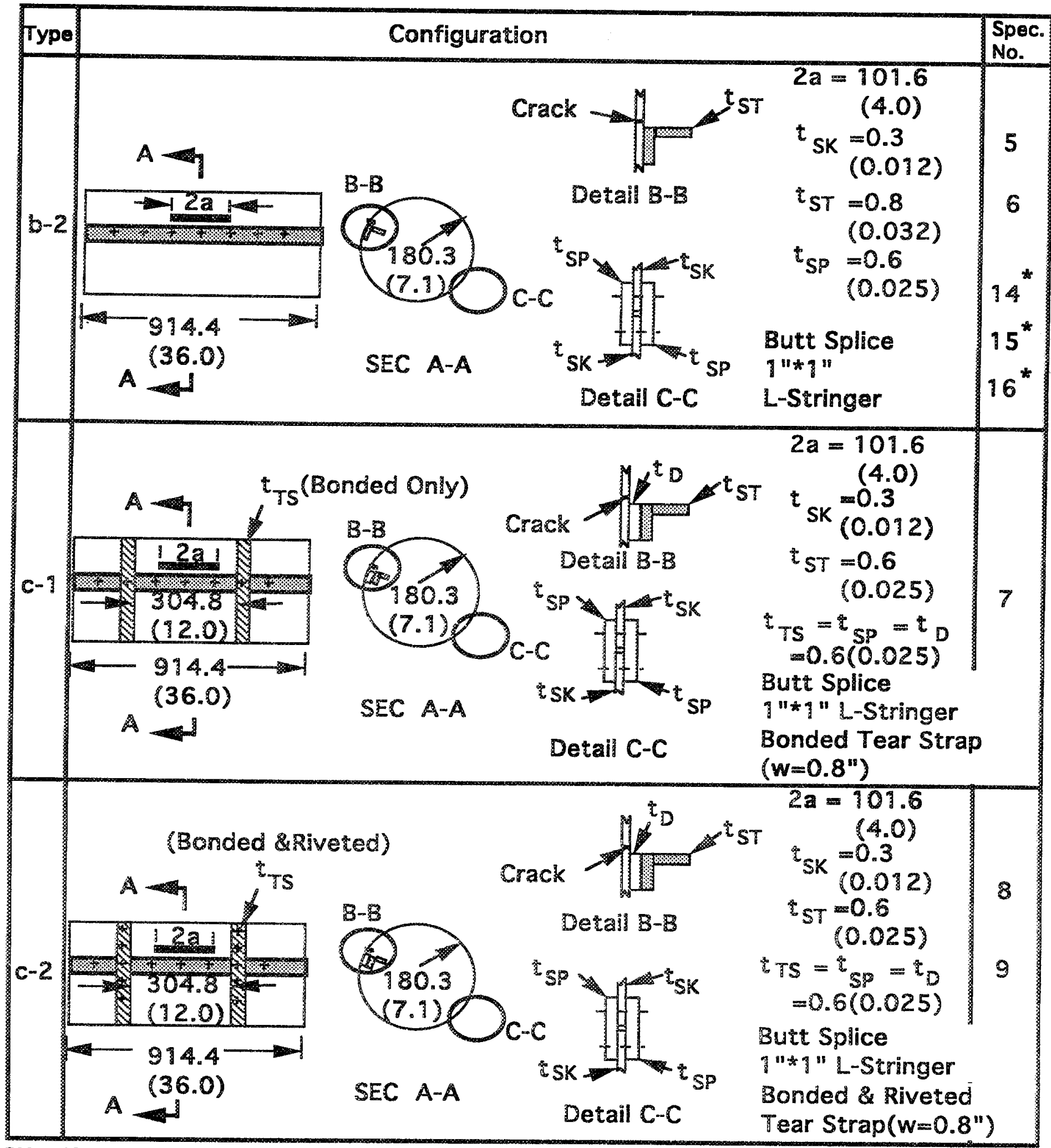

SK : Skin. ST : Stringer TS: Tear Strap SP: Splice Plate $D:$ Doubler Unit : mm * : Driven by the pneumatic riveter. 
Table 3. Small-Scale Fuselage Specimens

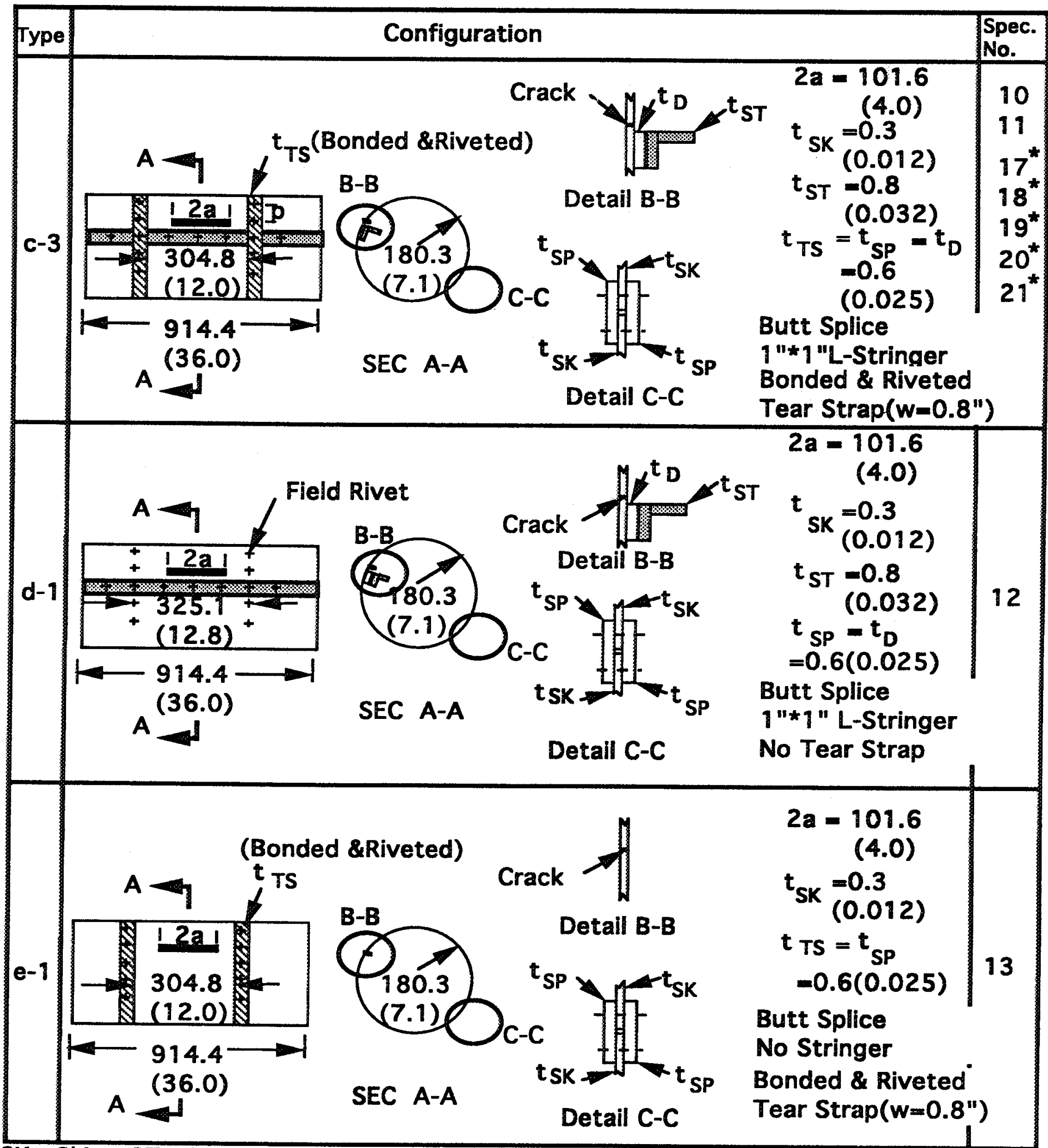

SK : Skin ST : Stringer TS : Tear Strap SP : Splice Plate D : Doubler Unit : mm * : Driven by the pneumatic riveter. 


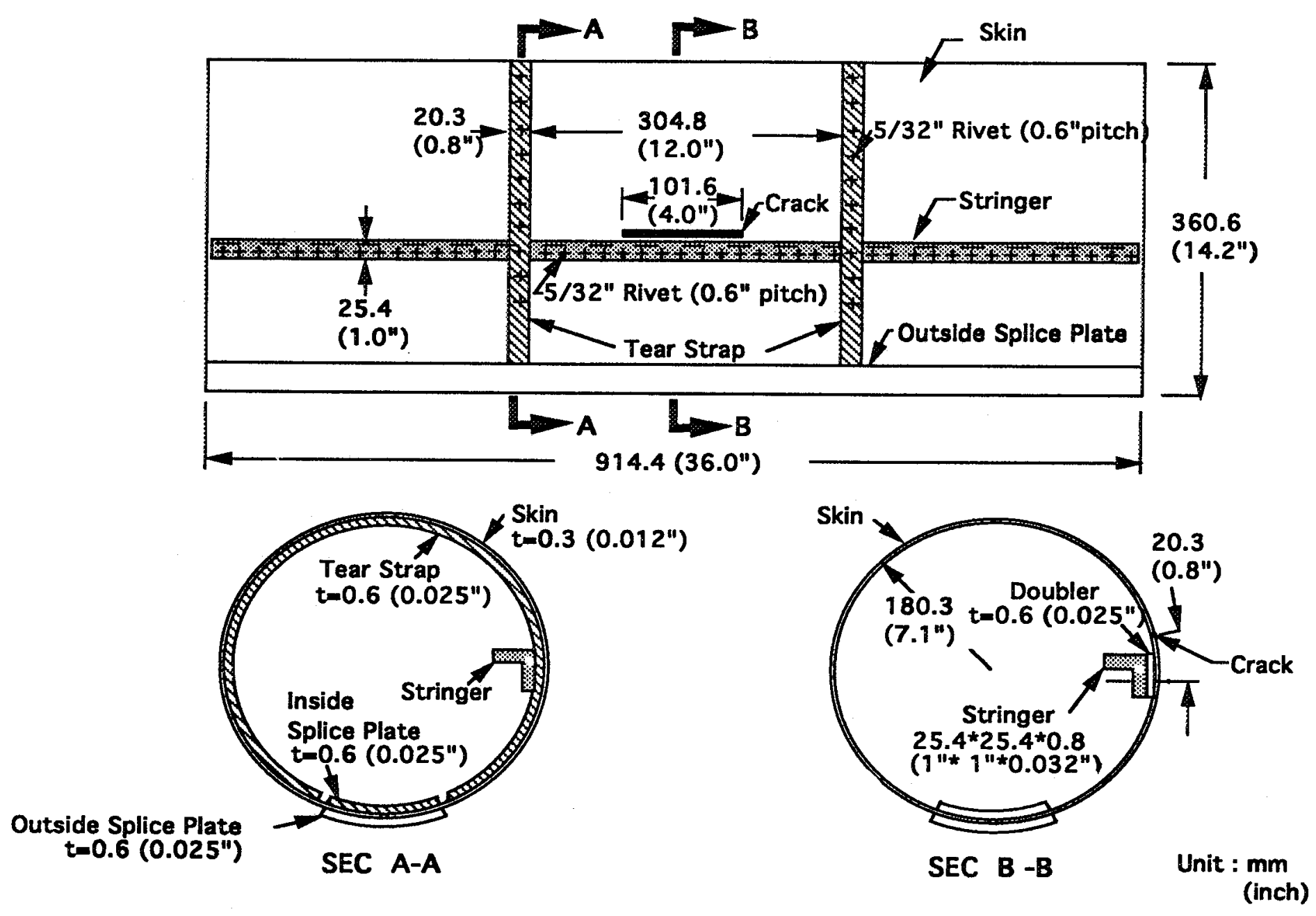

Figure 1. Scale model fuselage specimen. 


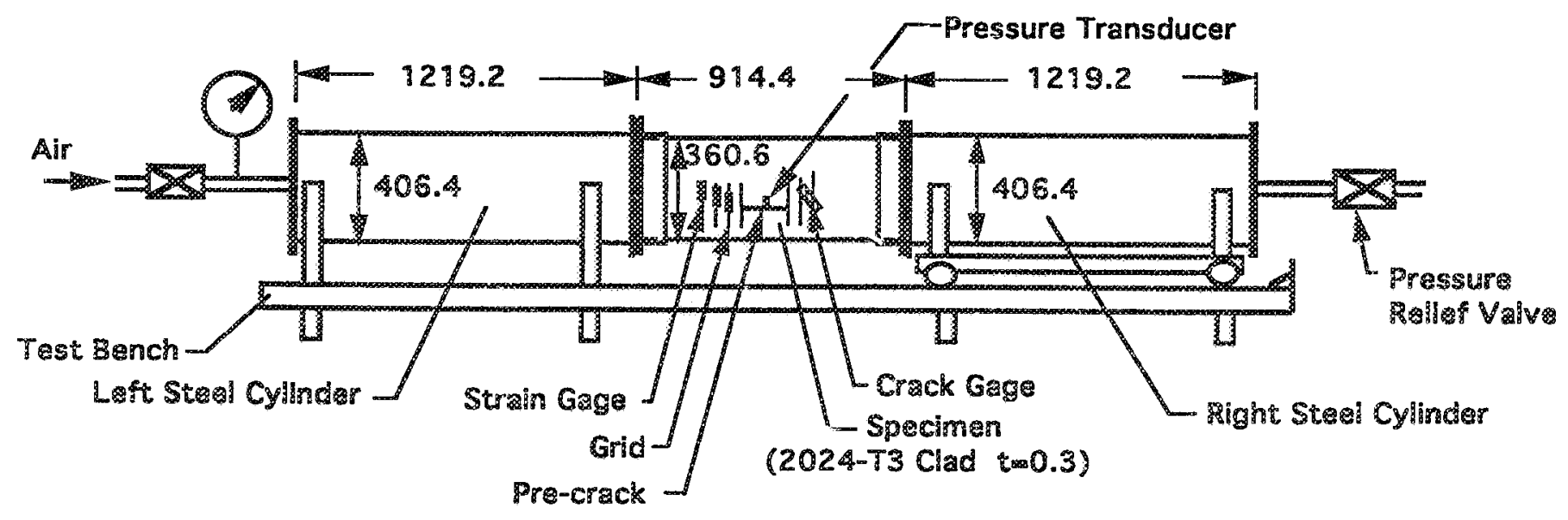

Unis: $\mathrm{mm}$

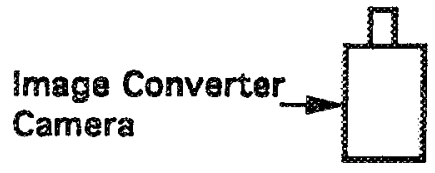

Figure 2. Test setup. 


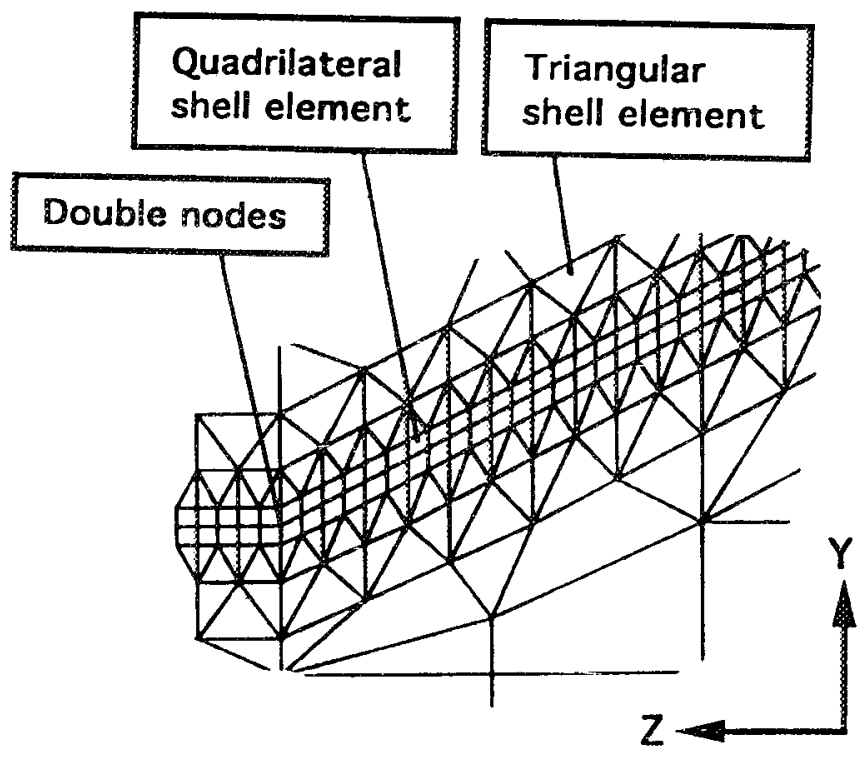

Detail of mesh along the crack path

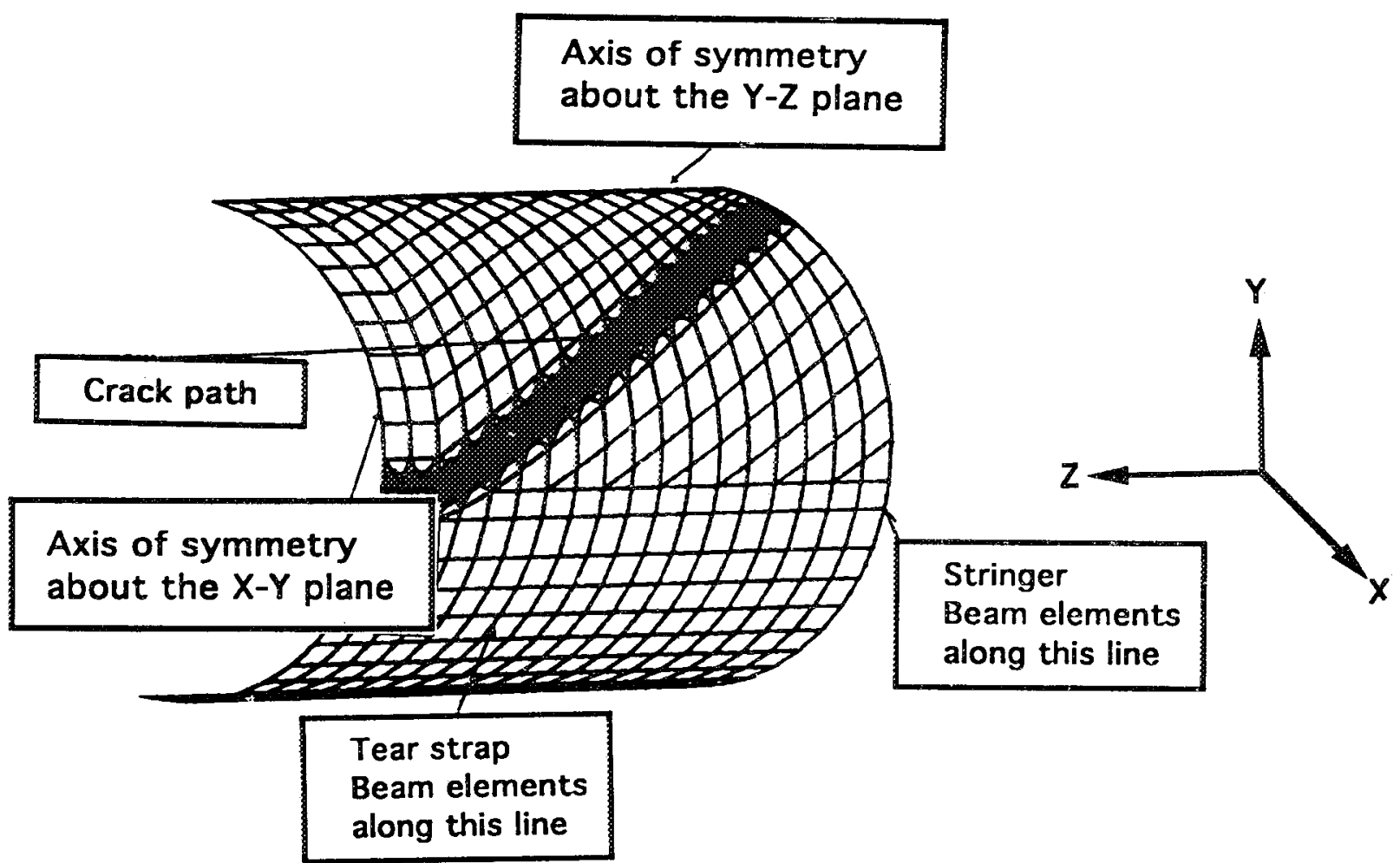

Figure 3. Finite element mesh. 


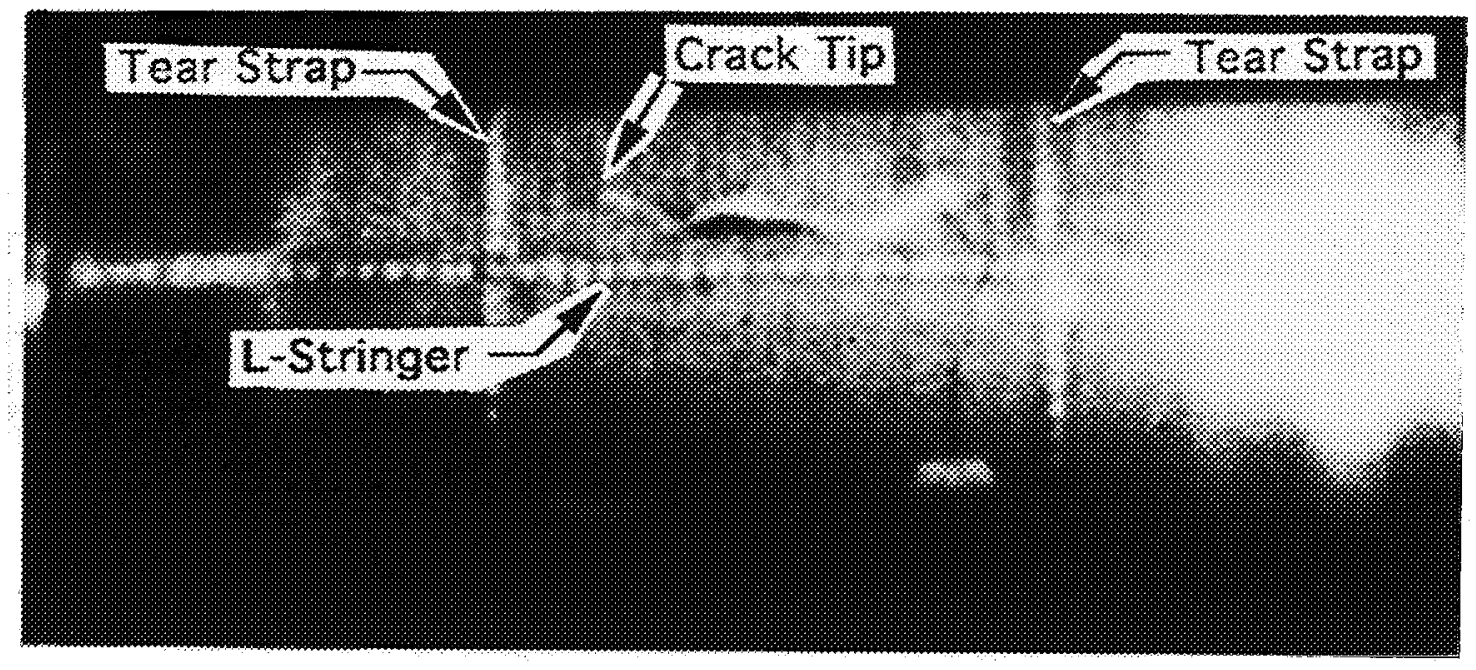

$$
\Delta t=0.4 \mathrm{msec}
$$

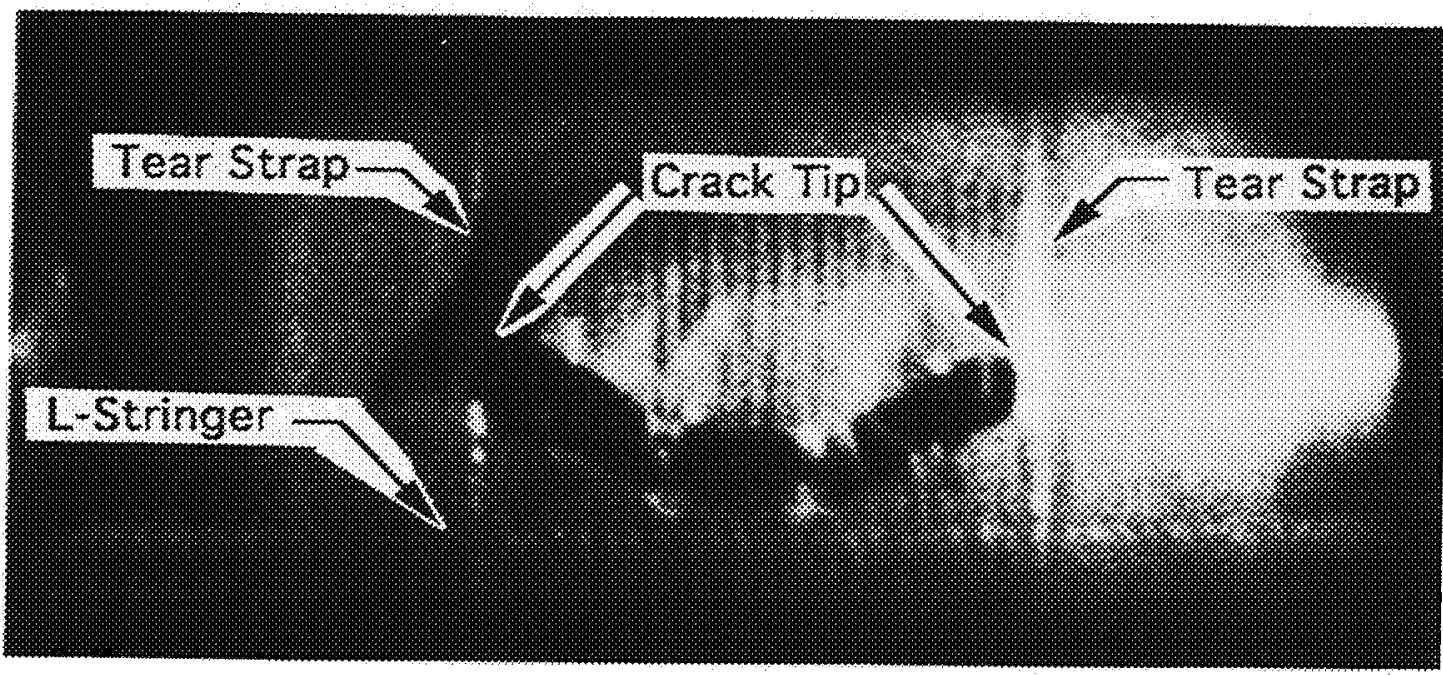

$$
\Delta \mathrm{t}=\mathbf{1 . 3} \mathrm{msec}
$$

$\Delta t$ : Delay time after the crack passed through the crack gage.

Figure 4. High speed photographs of a rupturing small-scale fuselage. Type c-3. 

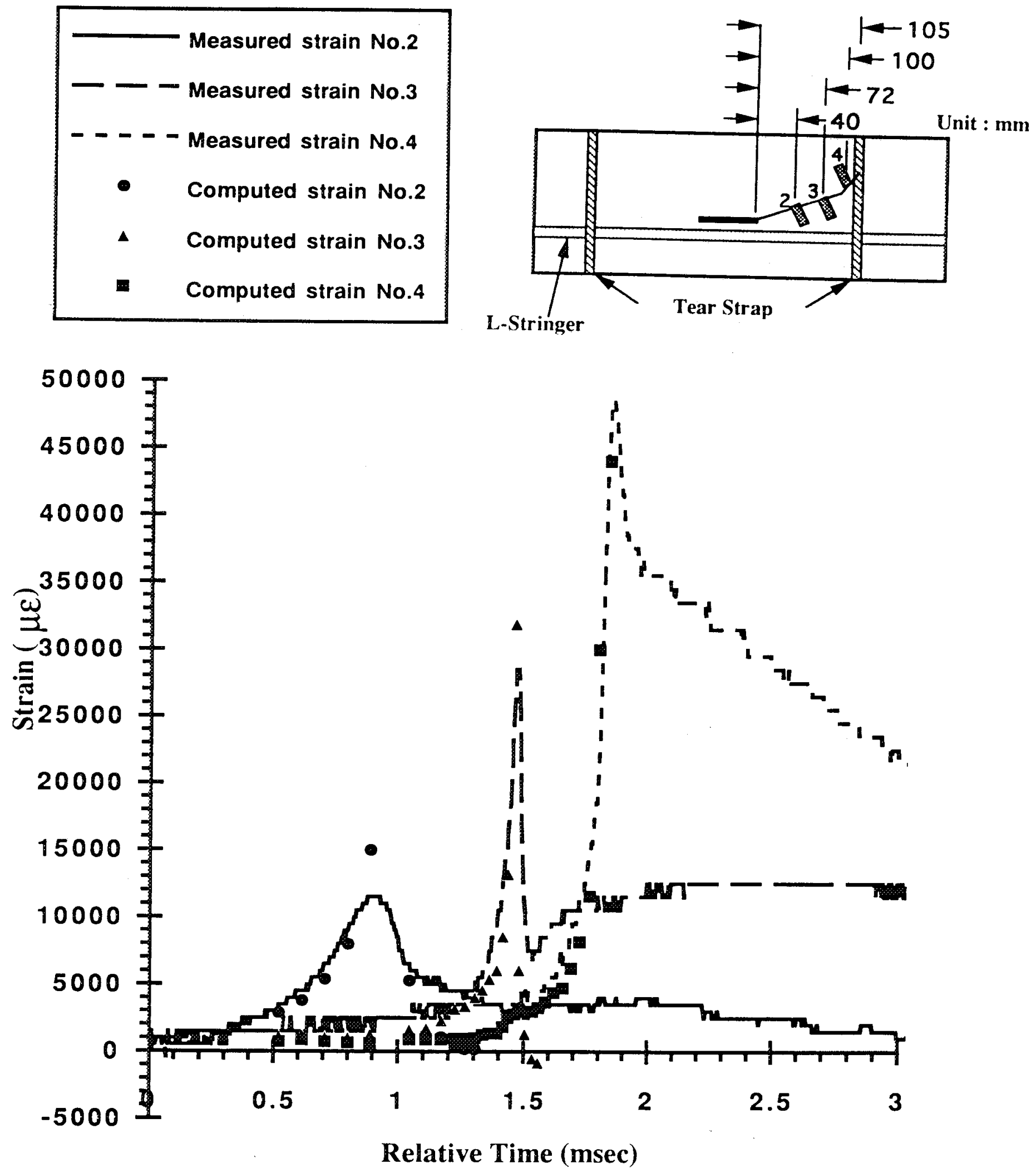

Figure 5. Strain gage response in Specimen No.11. Type c-3. 


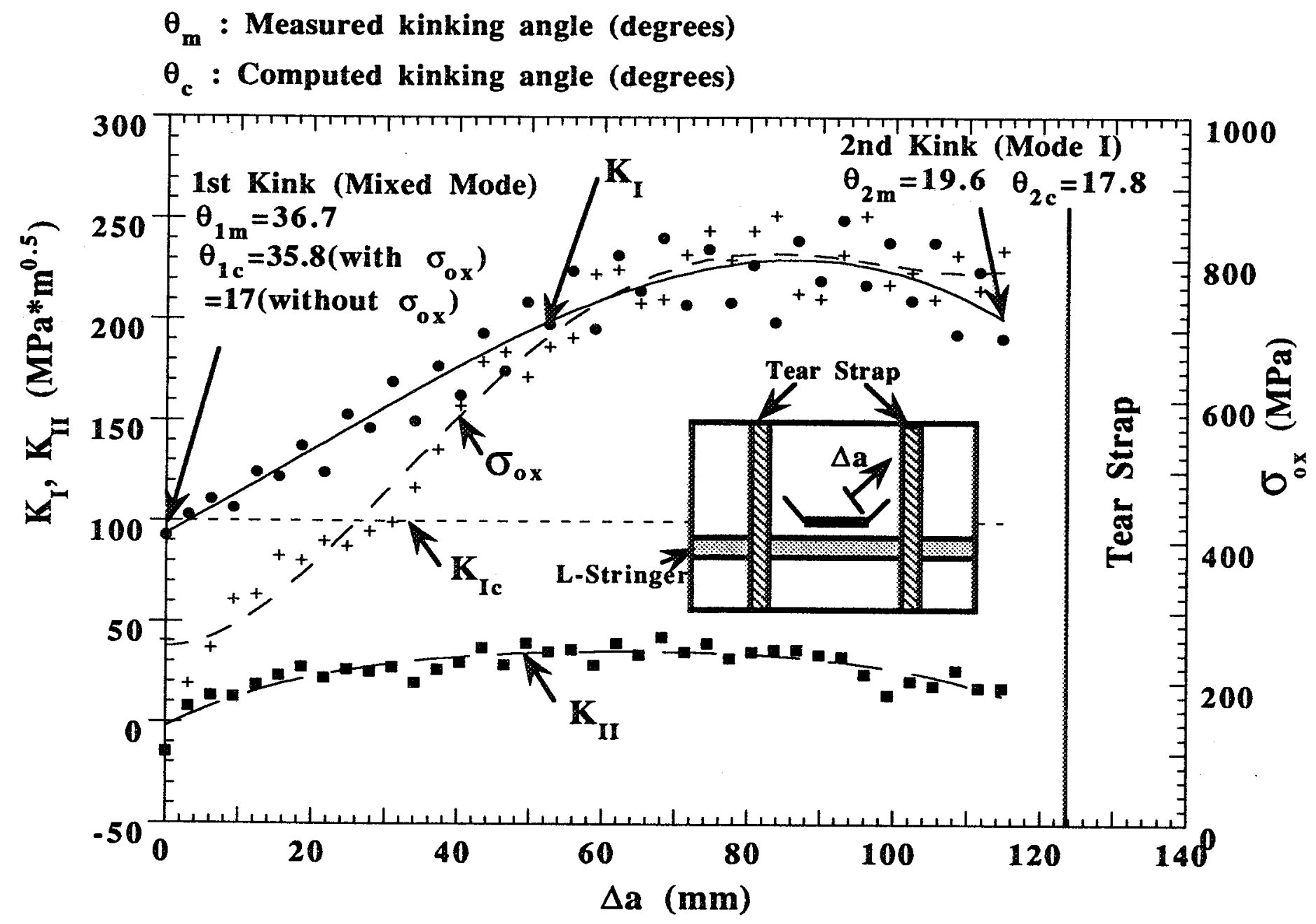

Figure 6. Variations in $K_{\mathrm{I}}, \mathrm{K}_{\mathrm{II}}$ and $\sigma_{\mathrm{ox}}$ with crack extension. Specimen No.11 (Type c-3). 


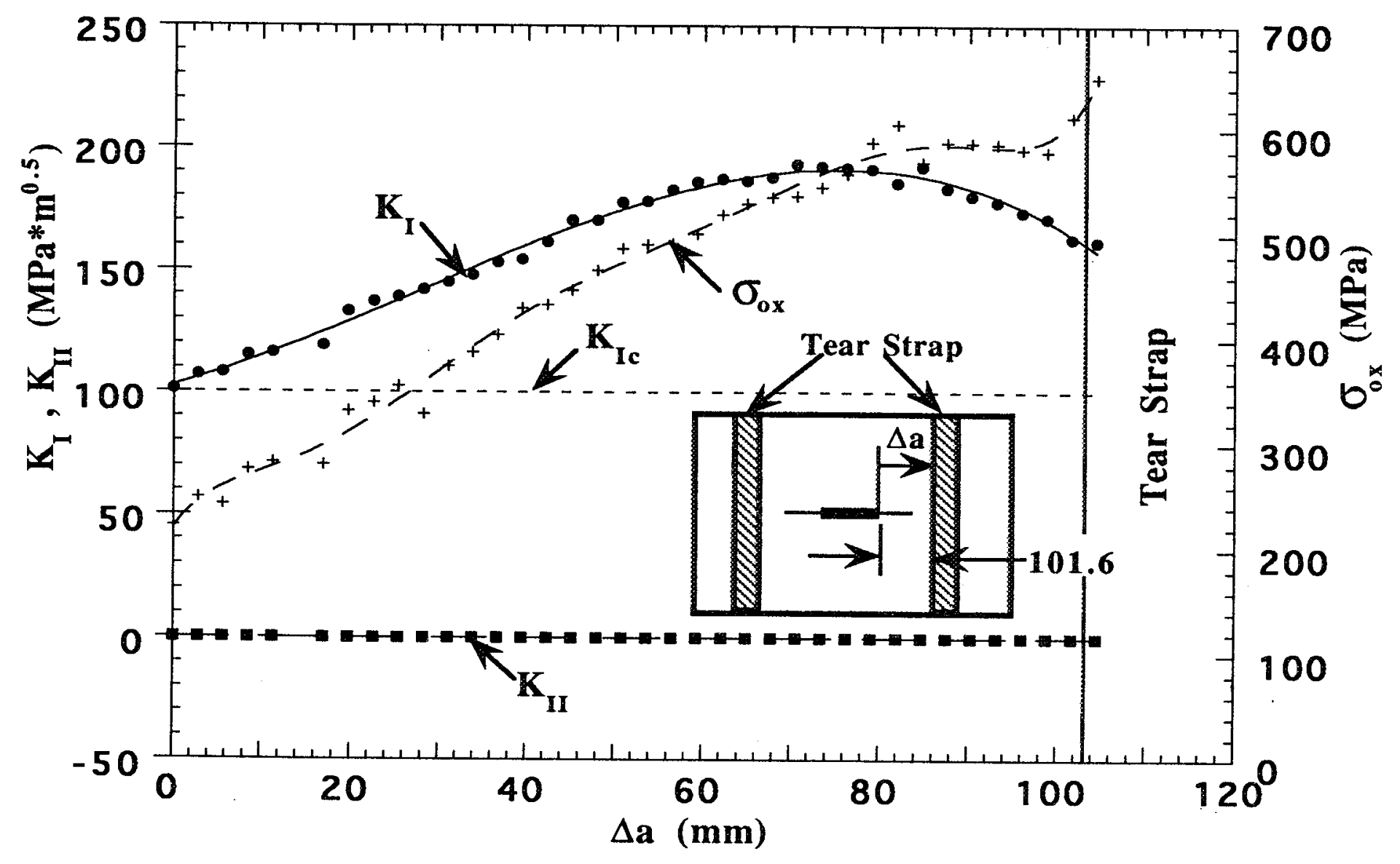

Figure 7. Variations in $\mathrm{K}_{\mathrm{I}}, \mathrm{K}_{\mathrm{II}}$ and $\sigma_{\mathrm{ox}}$ with crack extension. Specimen No.13 (Type e-1). 